\title{
El retrato de la otredad en la Relación de la jornada de Cíbola: recursos léxicos para la arabización del indígena
}

\author{
The Portrayal of the Other in the Relación de la jornada de Cíbola: Lexical \\ Devices for the Arabization of the Native American
}

\author{
Patricia Giménez-Eguíbar \\ Western Oregon University / IEMYRhd (Spain) \\ ORCID iD: https://orcid.org/0000-0002-1871-2239 \\ Sonia Kania \\ University of Texas at Arlington \\ ORCID iD: https://orcid.org/0000-0001-6339-6581
}

\begin{abstract}
Resumen
El presente artículo analiza los arabismos junto con otros recursos léxicos utilizados en la caracterización del indígena en la $R e$ lación de la jornada de Cíbola de Pedro de Castañeda, referida a la expedición que Francisco Vázquez de Coronado realizó entre 1540 y 1542 a los territorios del actual suroeste de los Estados Unidos. Tras una presentación general del texto, el trabajo se centra en el estudio de siete arabismos (alárabe, albarrada, alcoholar, alijar, atambor, borceguí y enjalma) junto con otras voces, entre ellas motes (Bigotes, Moro, Turco e Ysopete), para desentrañar los significados y las implicaciones sociolingüísticas del uso de estas voces aplicadas a la realidad americana y, para ello, se tienen muy en cuenta los datos proporcionados por las fuentes documentales y lexicográficas. Se parte de la premisa de que, en la conquista y colonización de Nueva España, se siguen los modelos de las precedentes conquistas granadina y norteafricana y, desde esta perspectiva de continuidad, se identifican medidas políticas paralelas, las mismas tradiciones discursivas, así como una actitud y conciencia lingüística comunes. Desde el punto de vista léxico, este intento de explicación del Nuevo Mundo se transmite a través de distintos procedimientos, entre ellos, el uso de arabismos léxicos con una función de ilustrar plásticamente una cultura desconocida y pagana a través de códigos familiares e igualmente paganos para el lector. La contribución ayuda a ensanchar el conocimiento sobre la presencia de arabismos en la historia del español.
\end{abstract}

Palabras clave: arabismos; conciencia lingüística; crónicas de Indias; lexicografía; tradiciones discursivas; estereotipos lingüísticos.

\begin{abstract}
This article analyzes the Arabisms and other lexical devices that are used to characterize the Native American in the Relación de la jornada de Cíbola by Pedro de Castañeda, a text that deals with the expedition that Francisco Vázquez de Coronado led to the present-day Southwestern United States from 1540 to 1542. After a general presentation of the text, the work focuses on the analysis of seven Arabisms (alárabe, alijar, albarrada, alcoholar, atambor, borcegui and enjalma) along with other words, including nicknames (Bigotes, Moro, Turco e Ysopete), to disentangle the meanings and sociolinguistic implications of the use of these words to refer to the American reality. In order to do so, great use is made of information garnered from documentary and lexical sources. We depart from the premise that in the conquest and colonization of New Spain, the models from the previous conquests of Granada and North Africa are followed. And through this perspective of continuity, we identify parallel political measures, identical discursive traditions, as well as a shared attitude and linguistic awareness. From a lexical point of view, this attempt to explain the New World is transmitted by various processes, including the use of lexical Arabisms to plastically illustrate an unknown and pagan culture through codes that are familiar, and equally pagan, to the reader. This contribution helps to expand our understanding about the presence of Arabisms in the history of the Spanish language.
\end{abstract}

Key words: Arabisms; linguistic awareness; chronicles of the Indies; lexicography; discoursive traditions; linguistic stereotypes.

Cómo citar / Citation: Giménez-Eguíbar, Patricia y Kania, Sonia, "El retrato de la otredad en la Relación de la jornada de Cíbola: recursos léxicos para la arabización del indígena", Al-Qanțara, 42, 2 (2021), e16. doi: https://doi.org/10.3989/ alqantara.2021.013 


\section{Finalidad de este estudio}

Nuestra intención en este trabajo es describir léxico utilizado en la representación de los nativos/indígenas en la Relación de la jornada de Cíbola de Pedro de Castañeda de Nájera, texto narrativo del siglo XVI que describe la expedición de Francisco Vázquez de Coronado de 1540-1542. Sin duda se trata de un texto interesantísimo desde varios puntos de vista, entre los que se pueden destacar el valor de la segunda parte de la Relación como modelo de representación geográfica y etnográfica, con listas toponímicas de una nueva frontera en un continente desconocido. Estamos ante un cronista cosmógrafo cuyo lenguaje, en palabras de Ahern, «titubeaba ante la pluralidad y poderío del terreno americano $»^{2}$. Asimismo, Castañeda es un testigo que pergeña un relato sobre la constatación de la derrota de una expedición, con una «trabajada estructuración y, en suma, una pensada poética del fracaso dirigida a un acto de promoción personal» ${ }^{3}$.

Por otro lado, queríamos comprobar la validez de algunos trabajos previos sobre estudios léxicos, al menos para el caso particular de los arabismos que aparecen en el texto. Antes de profundizar en el aspecto léxico, iniciamos el estudio con una contextualización del momento histórico. En última instancia, nos interesa conocer las implicaciones sociolingüísticas del uso de arabismos en textos que lidian con la descripción de los nativos de las Américas, específicamente, ¿por qué se recurre a modelos lingüísticos árabes para ciertos dominios, siendo además estos, muy concretos?

\section{Trasfondo del texto ${ }^{4}$}

La Relación de la jornada de Cíbola narra los eventos asociados con la expedición de Francisco Vázquez de Coronado por el actual suroeste de los Estados Unidos en 1540-1542. En el momento de embarcar en su jornada, o expedición militar, Coronado era el gobernador de Nueva

\footnotetext{
1 Para la tipología textual de la relación de Indias, véase Bravo-García y Cáceres-Lorenzo, La incorporación del indigenismo léxico, p. 91.

2 Ahern, "La narración cartográfica", p. 60

3 Escudero Baztán, "Una política del fracaso", p. 42.

4 Información extraída de Kania, Kauffeld y Sanz-Sánchez, Texts and Concordances, cuya transcripción paleográfica sirve de base para las citas textuales, también disponible en línea (véase Kania y Gago Jover, Colonial Texts). Otras fuentes para el trasfondo se citan debidamente.
}

Galicia, provincia al noroeste de Nueva España de la que dependía políticamente. La ciudad de Culiacán, en el actual estado de Sinaloa, fundada en 1531 por el anterior gobernador Nuño de Guzmán, representaba el límite norteño del conocimiento geográfico de los españoles en aquel entonces ${ }^{5}$. Partiendo oficialmente de Compostela, la antigua capital de Nueva Galicia, la expedición recorrería miles de kilómetros por una ruta que llevaría a los españoles al encuentro de nuevas culturas y nuevas tierras: la costa de Sinaloa, los desiertos de Sonora, las mesetas altas del río Colorado (en los actuales estados de Arizona y Nuevo México) y las llanuras de los bisontes (Texas, Oklahoma y Kansas) ${ }^{6}$.

Pedro de Castañeda, natural de Nájera y miembro de la expedición, escribe la Relación hacia 1560-15657. Se trata del testimonio más extenso que ha perdurado hasta nuestros días, y además, narrado por un testigo ocular ${ }^{8}$. Sobrevive en una única copia manuscrita que consta de 157 folios $^{9}$, producida en Sevilla en 1596, aparentemente en preparación para una edición impresa que nunca llegó a ver la luz. El texto está dividido en cuatro segmentos: un proemio (fols. $1 \mathrm{r}-6 \mathrm{v})$ seguido de tres partes - la primera parte (fols. 7r-94v), que contiene veintidós capítulos, la segunda (fols. 95r-125r), ocho capítulos y la tercera y última (fols. $125 \mathrm{v}-157 \mathrm{r}$ ), nueve.

En el proemio, Castañeda justifica la decisión de escribir la relación: una oportunidad de reivindicar la expedición y de sugerir una próxima colonización. La primera parte detalla los preparativos, así como los eventos hasta el verano de 1541, cuando Coronado y su compañía vuelven de la exploración a Quivira ${ }^{10}$, en el actual estado de Kansas. La segunda parte del texto, la más descriptiva, sirve de «glosa geográfica y etnográfica»

Ahern, "La narración cartográfica', p. 54.

6 Cf. Ahern, "La narración cartográfica', p. 59. Véase los mapas del área en Flint, No Settlement, pp. 251-256.

Castañeda explica que han pasado "ueinte años y mas" (fol. 2r) desde que la jornada se hizo. Aunque no tomáramos las palabras del autor como exactas, hay evidencia interna que revela que la fecha $a$ quo del texto es 1555 ya que en este año muere Juana de Castilla, cuya muerte se lamenta con la frase "que sea en gloria" (fol. 18r).

8 Para una síntesis de los principales rasgos lingüísticos del texto (aspectos gráficos y fonéticos, particularidades morfosintácticas y léxicas) véase Giménez-Eguíbar y Kania, "Los indigenismos léxicos".

9 MssCol 2570, no. 63 de la colección Obadiah Rich de la Biblioteca Pública de Nueva York.

10 Coronado conoce gracias al indio apodado El Turco la existencia de Quivira, una tierra casi mítica cuyos habitantes son los indios wichita (véase abajo). 
de la primera ${ }^{11}$. Castañeda comenta los aspectos culturales y físicos de los lugares de la expedición -Culiacán; Petatlán (Sinaloa); Chichilticale (Arizona); Cíbola, Tiguex y Cicuye ${ }^{12}$ (Nuevo México), los llanos de Cíbola y Quivira. La tercera parte narra los eventos asociados con la decisión de Coronado - controvertida, según el autor- de volver a Nueva España, así como el retorno mismo.

La organización del texto revela lo que parece ser el intento del autor de crear una relación de la cual el lector pueda extraer información histórica, geográfica y cultural de la expedición de Coronado, de sus miembros y, sobre todo, de la tierra y los pueblos encontrados. En el siguiente apartado, se analizan las técnicas usadas por Castañeda para describir esta nueva realidad.

\section{Procedimientos en la caracterización de la otredad}

La necesidad de dar nombre «a las cosas, a la naturaleza, a las innumerables especies vegetales y animales descubiertos, a las actividades y organización de los distintos grupos etnoculturales» exige que los conquistadores adaptaran la lengua a la nueva realidad ${ }^{13}$. En una primera etapa del contacto, se bautizaban con nombres familiares o voces patrimoniales las realidades que iban encontrando, por aproximación y semejanza $^{14}$. Así los bisontes de las llanuras son vacas, las tortillas de maíz son pan, los tipis de los indios nómadas son tiendas y las kivas ${ }^{15}$, estufas. El mismo concepto se utiliza en sentido más amplio en las descripciones que Castañeda provee de la vivienda, la ropa, la lengua, las prácticas sexuales, el sustento alimenticio y el paisaje donde el autor aplica su conocimiento sobre otras culturas para ubicar lo nuevo dentro de su esquema mental. Como explica Lawson-Peebles, «No existe tal cosa como [...] lo desconocido. Los que están por penetrar en una región sin explorar proyectan sobre ella una co-

\footnotetext{
$11 \quad$ Ahern, "La narración cartográfica", p. 54.

12 Cíbola, Tiguex y Cicuye se refieren a territorios de los pueblos, a saber, zuni, tiwa y towa, respectivamente. Los pueblos son así denominados por vivir en comunidades o pueblos. Habitan en casas de adobe, piedra y madera con techos planos, que pueden o bien tener varios pisos o niveles o ser viviendas de una sola altura. Véase el mapa de estos pueblos en Kessell, Spain in the Southwest, p. 38; Cicuye es el pueblo moderno de Pecos.

13 Buesa Oliver y Enguita Utrilla, Léxico del español de América, p. 29.

14 Torres Torres, Procesos de americanización.

15 'Recinto ceremonial de forma redonda construido en general bajo tierra' (Craddock, Acotaciones, p. 12).
}

lección de imágenes extraídas de su vivencia personal, de la cultura a que pertenecen, de los motivos del viaje y de sus ilusiones y temores acerca de su destino» ${ }^{16}$. De acuerdo con este procedimiento, Petatlán, el primer pueblo de esa «tierra nueva» se compara con la civilización de los tahúes de Culiacán (1):

\section{(1)}

Petlatlan es vna poblaçion de casas ... congregadas en pueblos que ban a el lue[n]go de vn rrio desde las sierras hasta la mar son gente de la calidad y rritos de los tahues culhacaneses ay entre ellos muchos someticos ... difieren en la lengua de los tahues algun tanto puesto que se entienden los vnos a los otros [fol. 101v]

Muchas de las descripciones incluyen referencias y comparaciones a la cultura española, visibles en sus explicaciones del tipo de construcción y vivienda de los indios pueblo. Por ejemplo, las casas de los zuni se organizan en barrios y carecen de patios (2a); sirven de construcciones defensivas (2b). Uno de sus pueblos tiene álabes ${ }^{17}(2 \mathrm{c})$. Se describen habitaciones características de las viviendas de los tiwa, como las kivas y sus retretes para moler maíz (2d-2e), o los corredores de las de los towa (2f):

a. es pueblo ... de tres y de quatro altos y las casas chicas y poco espaçiosas no tienen patios vn patio sirue a vn barrio [fol. 31v]

b. son casas particulares que siruen en el pueblo como de fortaleças que son superiores a las otras y salen por encima como torres y en ellas ay troneras y saeteras para defender los altos [fols. 55v-56r]

c. alli nos començo a nebar y faboreçiose la gente so las lasaues digo alaues del pueblo que salen afuera vnos como balcones con pilares de madera por baxo [fol. 56r]

d. daban por los sotanos que auian aportillado grandes humasos de suerte que pidieron la paz [fol. 62r]

e. tienen bien rrepartidas las casas en grande limpieça donde guisan de comer y donde muelen la harina que es vn apartado o rretrete donde tienen vn farnal con tres piedras asentado con argamasa [fol. 110r]

\footnotetext{
16 p. Ahern, “La narración cartográfica”, p. 55.

17 'Alero o ala de un tejado' [desus.] (DLE, s.v.).
} 
f. por lo alto se anda todo el pueblo sin que aya calle que lo estorbe a los dos primeros doblados es todo çercado de corredores que se anda por ellos todo el pueblo son como balcones que salen afuera y debajo de ellos se pueden amparar [fol. 112r]

Las comparaciones se aplican también a la descripción de la indumentaria. Tanto las mujeres de Sonora como las mujeres teya llevan sambenitos $^{18}(3 \mathrm{a}, 3 \mathrm{~d})$. Las mujeres hopi traen capotes y se arreglan el pelo en papos de cofia ${ }^{19}$ (3b). Los hombres tiwa llevan camisetas (3c) y las teyas faldellines (3d). La ropa de las hopi (3b) y de las teyas (3d) se equipara con mantas y paños de mesa:

a. Señora ${ }^{20}$ es vn rrio y ualle muy poblado de gente muy dispuesta las mugeres bisten naguas de cuero adobado de benados y sanbenitillos hasta medio cuerpo [fol. 101v]

b. andan cubiertas sus berguenças y todas las partes deshonestas con paños a manera de serbilletas de mesa con rrapasejos y vna borla en cada esquina ... las mugeres se bisten de mantas que las atan o añudan sobre el honbro isquierdo y sacan el braço derecho por ençima ... traen capotes de cuero pulidos de buena fayçion cogen el cabello sobre las dos orejas hechos dos rruedas que paresen papos de cofia [fols. 105r-105v]

c. trayan los hombres por alli camisetas de cuero de benado adobado y ençima sus pellones [fol. 111r]

d. traen mantas las mugeres sobre sus faldellines y mangas cogidas por las espaldas todo de cuero y vnos como sanbenitillos con rrapasejos que llegan a medio mu[s]lo sobre los faldellines [fols. $84 \mathrm{r}-84 \mathrm{v}$ ]

El paisaje se compara con el español. Se nombran lugares por sus características (4a) y se les asignan topónimos españoles (4b). Para entender la grandeza de la tierra nueva, se compara con conceptos conocidos $(4 \mathrm{c})$ y para convencer

18 'Capotillo o escapulario que se ponía a los penitentes reconciliados por el tribunal eclesiástico de la Inquisición' (DLE, s.v.).

19 Papo 'moda de tocado que usaron las mujeres, con unos huecos o bollos que cubrían las orejas' (DLE, s.v.). Cofia 'red de seda o hilo, que se ajusta a la cabeza con una cinta pasada por su jareta, que usaban los hombres y las mujeres para recoger el pelo' (DLE, s.v.).

20 Sonora, México. al lector de la utilidad de Quivira, se parangona con Castilla a la par que alaba la abundancia de flora (4d, 4e):

a. llegaron en quinse dias a ocho leguas de Çibola a vn rrio que por yr el agua turbia y bermeja le llamaron el rrio Bermejo en este rrio se hallaron barbos como en España [fol. 30v]

b. ueinte leguas adelante el rrio arriba auia vn poderoso y grande rrio digo pueblo que se decia Braba a quien los nuestros pusieron Ualladolid $^{21}$ [fols. 91v-92r]

c. determinaban vnos peñolsillos desgarrados de la barranca a el parecer de vn estado de hombre juran los que baxaron que llegaron a ellos que eran mayores que la torre mayor de Seuilla [fol. 46v]

d. la tierra era muy pareciente a la de España en las frutas y yerbas y temporales [fol. 94v]

e. se bio ser esta tierra muy aparente a la de España en su manera de yeruas y frutas ay siruelas como las de Castilla vbas nueçes moras uallico y abena poleo oregano lino en gran cantidad [fols. 122r-122v]

En esta línea de bautizar por aproximación y semejanza, los indios, la otredad, reciben nombres españoles (5a), a través de rasgos de su apariencia. Así, se utiliza el mote Bigotes para un cacique towa del pueblo Cicuye (5b). A otro indio, esclavo de Bigotes y natural de una zona al este de Quivira, se le conoce por El Turco (5c). Un indio de Quivira, también esclavo y rival de El Turco, recibe el nombre Ysopete, tal vez por tener aspecto griego, o quizá por su tatuaje $(5 \mathrm{~d})$.

(5)

a. para esto hiço llamar a vn indio principal de Tiguex ... a quien los nuestros llamauan Juan Aleman por vn Juan Aleman que estaba en Mexico a quien deçian pareçer [fol. 58v]

b. benia entre ellos vn capitan a quien los nuestros pusieron por nombre Bigotes porque traya los mostachos largos [fol. 48r]

c. a el indio llamaron Turco porque lo pareçia en el aspecto [fol. 51v]

d. yba en el campo otro indio pintado natural de Quiuira que se deçia Sopete [fol. 80v] 
Tal y como evidencian los motes El Turco e Ysopete, un tema recurrente en el texto es la equiparación del Otro con lo oriental y lo musulmán ${ }^{22}$. Las mujeres de la zona entre Petatlán y Chichilticale (6a) y las querecho (6b), por poner otros ejemplos, se equiparan a aquellas norteafricanas.

(6)

a. son las gentes de la calidad de los de Señora ... las mugeres se labran en la barba y los ojos como moriscas de Berberia [fol. 102v]

b. aqui se hallo vna india tam blanca como muger de Castilla saluo que tenia labrada la barua como morisca de Berberia [fol. 82r]

El énfasis en lo exótico es evidente así como el discurso cargado de elementos raciales. La descripción etnográfica se hace en aras a las similitudes de una cultura conocida para el lector: la musulmana. Este concepto se desarrolla en el apartado siguiente a partir del análisis del léxico seleccionado para describir dicha realidad.

Por último, cabe destacar la presencia de un auténtico bereber en el texto, Estebanico el Negro, también conocido como El Moro. Se trata de un superviviente de la malograda expedición de Pánfilo de Narváez, natural ${ }^{23}$ de Azamor (Marruecos), que participa en la odisea de Cabeza de Vaca. Dada su experiencia en estos parajes, se le envía como guía en la expedición de fray Marcos de Niza, aunque es un personaje del que no se fía ninguna de las dos partes: ni españoles (7a) ni indios (7b):

(7)

a. pareçe que el negro no yba a fabor de los frayles porque lleuaba las mugeres que le daban y adquiria turquesas y haçia balumen de todo y aun los indios de aquellos poblados por do yban entendiasen mejor con el negro como ya otra uez lo auian uisto [fols. 11v-12r]

b. les pareçio desbario decir que la tierra de donde uenia era la gente blanca siendo el negro y

22 «El Otro exterior es medido, casi sistemáticamente al principio de la conquista, en los términos conocidos para el Otro interior (sobre todo musulmán, pero también judío) y los ejemplos son demasiado abundantes como para poder incluir aquí algo más que una muestra» (García-Arenal, "Moriscos e indios", p. 162).

23 Su nombre original era Mustafa, pero recibe nombre cristiano al convertirse al catolicismo durante su cautiverio en España. Andrés Dorantes hacia 1520 lo compró como esclavo. Véase Manseau, One Nation. enbiado por ellos y fueron a el y como despues de otras rraçones le[s] pidiese turquesas y mugeres pareçioles cosa dura y determinaronse a le matar [fol. 14r]

La desconfianza que sienten los españoles hacia el Otro también repercute en los personajes indígenas mencionados anteriormente. Tanto Bigotes como El Turco acaban siendo prisioneros de los españoles. Después de ser encadenado y preso, se libera finalmente a Bigotes. El Turco, sin embargo, muere agarrotado por ser el principal sospechoso en el complot Pecos ${ }^{24}$, a saber, una trampa que los líderes de los towa supuestamente habían organizado para llevar a los españoles hacia Quivira por una ruta tortuosa, donde se perderían o morirían de inanición ${ }^{25}$. La amenaza del enemigo turco es una idea fija en el pensamiento español de la época, como se verá a continuación.

\section{Los arabismos}

En numerosas ocasiones se ha señalado que los arabismos léxicos se convirtieron en un recurso muy utilizado en las crónicas para describir la nueva realidad americana ${ }^{26}$. Para ilustrar esta tendencia se han proporcionado ejemplos provenientes de los textos de Colón: la canoa es almadia, los indios son gandules, azagayas son sus armas, alfaneques sus casas y alcatraz el pelícano americano, afirma Morínigo ${ }^{27}$; taparrabos almaizares, los indios-guía adalides añaden Bravo-García y Cáceres-Lorenzo ${ }^{28}$. Asimismo, Cortés utiliza los términos alfaquís y mezquitas ${ }^{29}$ en sus cartas desde México, alude a las habitaciones moriscas, llama al maíz grano turco, y el mercado mexicano, en su opinión, «parece propiamente la alcaicería de Granada ${ }^{30}$. Esta

24 Cf. Riley, Rio del Norte, pp. 180-181.

25 Flint (No Settlement, pp. 167-169), por su parte, no cree que El Turco fuera culpable, sino que la actitud de los españoles era el resultado de su tradición de excesiva desconfianza en los guías. Añade, además, que las confesiones que consiguen los españoles sobre el supuesto complot se sacan mediante tortura.

26 Morínigo, "La formación léxica", pp. 234-235; Marcos

Maíllo, "Los arabismos más utilizados”, pp. 230-237; Bravo-García y Cáceres-Lorenzo, La incorporación del indigenismo léxico, pp. 55-56; Bastardín Cardón, "La adaptación del fondo léxico patrimonial", p. 37.

27 Morínigo, "La formación léxica", p. 234.

28 Bravo-García y Cáceres-Lorenzo, La incorporación del indigenismo léxico, p. 56.

29 Bunes Ibarra, "El descubrimiento de América", p. 228; Marcos Maíllo, "Los arabismos más utilizados", pp. 228-235; Manseau, One Nation, p. 42.

30 Cf. García-Arenal, "Moriscos e indios", p. 162 
particular presencia léxica se ha explicado debido a la procedencia de los exploradores ${ }^{31}$, la creencia de hallarse en las Indias Orientales ${ }^{32} \mathrm{o}$ como recurso para designar lo exótico ${ }^{33}$. Otros estudios sugieren que esta tendencia se atenúa y se reemplaza por la incorporación de indoamericanismos ${ }^{34}$. No obstante, salta a la vista la naturaleza parcial de dichas explicaciones a este uso recurrente en los textos coloniales. A continuación, se propone una nueva perspectiva a la luz de las tradiciones discursivas ${ }^{35}$, ya que estas tienen un papel central en la divulgación de innovaciones lingüísticas $y$, paralelamente, proporcionan el eslabón hermenéutico entre los factores externos (sociales, culturales) e internos a la lengua, aspecto capital en el estudio de la historia del léxico. De hecho, las tradiciones propician el mantenimiento de ciertos elementos lingüísticos, como a continuación se demuestra con ciertos arabismos, sin apenas productividad ni frecuencia en variedades lingüísticas peninsulares, que exhiben una renovada vitalidad en la tradición discursiva de los textos coloniales novohispanos. Según Kabatek, «el rasgo que define las tradiciones discursivas es, entonces, la relación de un texto en un momento determinado de la historia con otro texto anterior: una relación temporal a través de la repetición de algo» ${ }^{36}$.

Por otro lado, los historiadores coinciden en que la colonización de Nueva España sigue los modelos de las precedentes conquistas granadina y norteafricana; de hecho, los exploradores estaban formados en la frontera de Granada ${ }^{37}$ y pertenecían a «las últimas generaciones de espa-

\footnotetext{
31 Menéndez Pryce, "Léxico de Cuba", pp. 101-102.

32 Morínigo, "La formación léxica", p. 234.

33 Marcos Maíllo, "Los arabismos más utilizados”, p. 228.

34 Valdés Bernal, Inmigración y lengua nacional, p. 127; Bravo-García y Cáceres-Lorenzo, La incorporación del indigenismo léxico, pp. 55-56; Bastardín Cardón, "La adaptación del fondo léxico patrimonial", p. 37.

35 «Se trata pues de modelos o esquemas histórico-contingentes que guían la producción y recepción de cualquier texto o discurso y que, si bien rebasan el marco de las lenguas individuales, seleccionan en éstas (al menos parcialmente) el uso de una variedad lingüística o modelos verbalizadores determinados» (Gallego Shibya, "Tradiciones discursivas y variación lingüística”, p. 14).

36 Kabatek, "Tradiciones discursivas y cambio lingüístico" p. 154.

37 «Las bases ideológicas de la conquista de Nueva España deben mucho a la exaltación mesiánica producida en to[rn]o a la Conquista de Granada que incluye sueños de conversión universal y la percepción de una lucha cósmica entre la Cristiandad y el Islam» (García Arenal, "Moriscos e indios", pp. 154-155).
}

ñoles imbuida de mudejarismo» ${ }^{38}$. En el Nuevo Mundo se encuentran las últimas repercusiones del Islam ibérico, del mismo modo «en que la percepción y la consideración de las poblaciones indígenas americanas tuvieron peso de consideración para las ideas acerca del moro o del musulmán como 'otro' por antonomasia ${ }^{39}$.

La revisión de la producción literaria sobre la guerra de Granada, el norte de África y las crónicas de Indias, confirma este paralelismo en las actitudes, espíritu ${ }^{40}$, objetivos, descripciones geográficas, etnográficas, ambientales ${ }^{41} \mathrm{y}$, como no podía ser de otra manera, en las formas lingüísticas en las que tales se articulan. Estos textos configuran, efectivamente, una tradición discursiva, es decir, «hábitos comunicativos característicos para determinados grupos sociales o culturales» en los que los cronistas convienen en la misma actitud respecto a los arabismos léxicos, dado que comparten idéntica conciencia lingüística propia de su comunidad sociocultu$\mathrm{ral}^{42}$. Efectivamente, esta comunidad presenta unas características determinadas históricamente que permiten analizarla como una red social densa, jerarquizada, en la cual el cronista goza de un estatus central definido por su profesión.

Nos hemos ocupado con anterioridad de algunas cuestiones respecto a los préstamos árabes y su evolución en el español peninsular,

\footnotetext{
38 Bunes Ibarra, "El descubrimiento de América"; García-Arenal, "Moriscos e indios"; Manseau, One Nation, pp. 29-56.

39 García-Arenal, "Moriscos e indios", p. 153. Véase el trabajo de García-Arenal sobre la idea de Cruzada presente en todas estas empresas de expansión, es decir, el marco mesiánico de la mentalidad de los conquistadores en la empresa americana: la inminencia del fin del mundo, la urgencia de cristianizar, recuperar la Tierra Santa y convertir a la Fe las indias occidentales. García-Arenal considera particularmente significativa la Cruzada y conquista de Orán (1509) que profetiza el fin definitivo del Islam y la conversión al cristianismo de toda la humanidad. Eran, como afirma la autora, hombres creados por la sociedad formada tras dos siglos de guerra de frontera con Granada.

40 Bunes Ibarra, "El descubrimiento de América", pp. 226-227; García-Arenal, "Moriscos e indios", pp. 153-154.

41 «As unlikely as it seems, they frequently reacted as if the people encountered on the other side of the Atlantic were Muslims. This is not to say they truly believed the Indias had any connection to Islam. Rather, because the Spanish saw humanity defined and separated by known religious differences, they lacked a category for the native peoples of the Americas, and so used one of their existing categories to make sense of a form of difference they were encountering for the first time» (Manseau, One Nation, p. 42).

42 Becker, "Tradiciones discursivas", p. 107; Cf. Giménez Eguíbar, "Algunas cuestiones".
} 
sobre todo el siglo $\mathrm{XVI}^{43}$, momento en el que identificamos la existencia de una conciencia lingüística antisemítica por parte de algunos autores áureos hacia estos préstamos ${ }^{44}$. También es sabido que una política lingüística hacia la lengua árabe en la península, junto con el proceso de estandarización del español peninsular, acaba convirtiendo los arabismos en términos marcados sociolingüísticamente ${ }^{45} \mathrm{y}$ abocando eventualmente a los más prominentes, es decir, los que se identificaban más fácilmente con la minoría semítica, a un proceso de obsolescencia léxica ${ }^{46}$.

Desde el punto de vista léxico, este intento de explicación del Nuevo Mundo se transmite a través de distintos procedimientos. Por ejemplo, el uso de extensiones semánticas o americanismos léxicos (vide supra), los indigenismos ${ }^{47}$ y en ocasiones, con arabismos léxicos, que se utilizan para ilustrar con mayor plasticidad una cultura desconocida y pagana a través de códigos familiares, e igualmente paganos, para el lector. Desde el punto de vista lingüístico, el uso de arabismos constituye una de las formas de explicar el Otro exterior en términos del Otro interior «musulmán».

Se ha de hacer hincapié en que no puede entenderse la función de los arabismos en los textos cronísticos sin tener en cuenta el contexto histórico y la ideología imperante de la época. Con este objetivo en mente, a continuación, se proporcionan ejemplos de este uso en la Relación. Tras la lectura atenta del texto, se han seleccionado los siguientes: alárabe, albarrada, alcoholar, alijar, atambor, borceguí у enjalma. Cabe también señalar que la Relación contiene, como es lógico, arabismos generales al español de las dos orillas. Una última puntualización: se utiliza arabismo en sentido amplio ya que bajo esta etiqueta se incluyen los derivados formados con base árabe, pero incorporados al castellano, junto con la aplicación de sufijos y prefijos y con cambio semántico ya en romance. En esta misma línea, se considera arabismos tanto los directos como los que se transmiten por vía indirecta.

43 Giménez Eguíbar, "Hacia una elaboración”.

44 Giménez Eguíbar, "Attitudes Toward Lexical Arabisms".

45 Giménez Eguíbar, “Algunas cuestiones”; Giménez Eguíbar, "Attitudes Toward Lexical Arabisms".

46 Giménez Eguíbar, "Dos casos de sustituciones léxicas".

47 Giménez-Eguíbar y Kania, "Los indigenismos léxicos".

\subsection{Alárabe $^{48}$}

La denominación se usa en dos ocasiones $(8 \mathrm{a}, 8 \mathrm{~b})$ para referirse a los querechos, un grupo nómada que vive de la caza de los bisontes ${ }^{49}$.

(8)

a. a otras diez jornadas dieron en vnas rrancherias de gente alarabe que por alli son llamados querechos [fol. 78r]

b. andan como alarabes con sus tiendas y harrias de perros [fol. 120v]

El LHA proporciona multitud de ejemplos que ilustran el fructuoso uso que se hace del gentilicio, en línea con esta tradición discursiva a la que nos referíamos. He aquí un ejemplo ${ }^{50}$ :

c. [1535 Ciudad de Santo Domingo] salvaje a manera de alárabes la vida que ellos hazían [RBN 5, 390].

A continuación, se facilita un ejemplo de CORDIAM de Francisco Cervantes de Salazar en su Crónica de la Nueva España de $1566^{51}$ :

d. Hay otros indios que llaman chichimecas, que siguen la costumbre de los alárabes, no tiniendo casa ni morada cierta, ni labrando los campos de que se sustenten

Se trata de un término con la etiqueta de $p$. us. (poco usado) según el $D L E^{52}$. Según Corriente es un 'Bedouin; barbarian' 53 . El DHLE en la tercera acepción lo define como 'hombre incivil, inhumano' y para ello se basa en la definición

48 La disposición de las entradas léxicas es a saber: en primer lugar, las voces estudiadas en su fuente (la Relación), a continuación, los testimonios en otras fuentes coetáneas extraídos principalmente del Léxico hispanoamericano del siglo XVI (LHA), Corpus diacrónico del español (CORDE) y, por último, el Corpus Diacrónico y Diatópico del Español de América (CORDIAM). Finalmente, se presentan los testimonios de los repertorios lexicográficos: Diccionario de la lengua española (DLE), Dictionary of Arabic and Allied Loanwords: Spanish, Portuguese, Catalan, Gallician and Kindred Dialects de Corriente, Diccionario crítico-etimológico castellano e hispánico $(D C E C H)$, Diccionario histórico de la lengua española (DHLE), además de las obras de los lexicógrafos áureos, académicos y extraacadémicos disponibles en el Nuevo tesoro lexicográfico de la lengua española (NTLLE). Se han consultado puntualmente otras obras, que se indican en su momento.

49 Los querechos son los apaches de las llanuras (véase Hickerson, The Jumanos, pp. 23-24).

$50 L H A$, s.v. Véase este corpus para más ejemplos y para la identificación de las obras (representadas por siglas).

51 CORDIAM, s.v.

52 DLE, s.v.

53 Corriente, Dictionary, s.v. alárabe. 
tanto de Rosal (de 1601): 'Llamamos Alarbes a los que no guardan policia ni urbanidad' como de Autoridades (de 1726): 'Vale tanto como hombre bárbaro, [...] áspero, bestial [...]. Dícese por comparación a la brutalidad y fiereza que se experimentó en los Árabes o Alárabes que posseyeron a España' ${ }^{54}$. La acepción 'nómada' del DHLE coincide con el sentido utilizado en el texto ${ }^{55}$. Según Craddock, se emplea como 'salvaje' o mejor 'indio nómada' en contraste con los indios pueblo de vivienda fija ${ }^{56}$.

La identificación de ambos grupos étnicos en el ideario español es evidente y la utilización de arabismos para la transmisión de esta idea quedará ilustrada a continuación.

\subsection{Albarrada}

Si bien la etimología está lejos de ser clara ${ }^{57}$, dejando al margen por ahora el origen, lo cierto es que se trata de una forma arabizada que en nuestro texto se inserta en la descripción de la fortaleza enemiga cuando los españoles llegan a Acuco, el actual Ácoma ${ }^{58}$, en el sentido de 'cerca de protección de guerra' ${ }^{59}$.

en lo alto avia vna albarrada de piedra seca y grande que sin se descubrir podian derribar tanta que no fuese poderoso ningun exerçito a les entrar [fols. 49v-50r]

Se trata de una denominación frecuente en las crónicas bélicas de la Reconquista (como por ejemplo la de Hernando del Pulgar ${ }^{60}$ ). Habida cuenta del marco de continuidad de ambas empresas bélicas al que se aludía al inicio, tiene

54 DHLE, s.v.

55 DHLE, s.v.

56 Craddock, “Acotaciones", p. 11.

57 DCECH, s.v. parar: "del lat. PARARE 'preparar', 'disponer', 'proporcionar'. [...] Todos los indicios fonéticos y semánticos revelan que parata y albarrada no pueden venir del ár. balât 'calzada' (BALATE)". Por otro lado, Corriente lo define como 'dry wall'; de la etimología de Corominas y Pascual opina: «his proposal of a L[atin] etymon ** părāre 'to prepare' may be naive, considering that Alcala, as And[alusian] equivalent of albarrada gives $>$ xipar $<$, i.e., šipar, no doubt a reflex of L[atin] siparium 'curtain; sunshade'» (Dictionary, s.v. albarrada I).

58 Un pueblo queres que está construido sobre una meseta de más de 100 metros de altura (Julyan, The Place Names, p. 3).

59 DLE, s.v.

60 «E açaeció que el rey moro, ynformado que el Rey quería poner çerco sobre Moclín, [...] el qual puso parte de su gente dentro en vna albarrada, bien çerca de la villa». [Hernando del Pulgar, Crónica de los Reyes Católicos, España, 1480-1484] (CORDE, s.v.). sentido que los cronistas de Indias la utilicen en aras a aportar una mayor plasticidad a la descripción de esta construcción defensiva del enemigo. De hecho, Cortés la utiliza tres veces en su Segunda carta de relación, treinta y nueve veces en la Tercera carta de relación y quince veces en su Cuarta carta de Relación ${ }^{61}$.

El LHA provee una veintena de ejemplos utilizados en esta misma acepción que se extienden hasta finales del siglo XVIII ${ }^{62}$. Guadix y el Padre Alcalá, documentan esta voz en los repertorios lexicográficos bilingües árabe español del siglo $\mathrm{XVI}^{63}$.

\subsection{Alcoholar}

Este derivado denominal se halla en una descripción rica en detalles étnicos de una india nativa:

a. aqui se hallo vna india tam blanca como muger de Castilla saluo que tenia labrada la barua como morisca de Berberia que todas se labran en general de aquella manera por alli se ahogolan los ojos [fol. 82r]

No parece azarosa la elección de la unidad fraseológica alcoholar los ojos (frente a utilizar afeites, por ejemplo) sino una elección consciente para reproducir una forma de representación cosmética que, por un lado, hiperboliza el contraste entre la blancura de la india con la negrura del tatuaje y de los ojos y, por el otro, crea una producción textual cargada de elementos raciales cuando se examina desde una perspectiva material. Para sustentar esta afirmación basten los numerosos ejemplos de esta unidad fraseológica provistos por el $L H A$ en la caracterización del indio ${ }^{64}$ :

b. [c. 1548 Nuevo Reino de Granada] el Río Grande de Cartagena que está poblado de unos indios llamados Cendaguas alcoholados [DIH 9, 218]

[c. 1549 Ciudad de Santo Domingo] cuando alcanza la tercera vitoria, píntanle desde los

\footnotetext{
61 Por aportar uno de los muchos ejemplos de Kania y Gago Jover, Colonial Texts: «E yendo nos adelante halle en vn passo muy estrecho vna albarrada de palizada fuerte y enella no auia gente ninguna» [Hernán Cortés, Cuarta carta de relación, Toledo, 1525].

$62 L H A$, s.v.

63 «Albarrada llaman en España a un hormazo hecho de piedra, vigas, o barrones de madera o de çestones y fagina, que vale Para detener gente, o cauallos, o Río, o otro qualquiera ímpetu» (Guadix, Diccionario de arabismos, s.v.).

64 LHA, s.v. alcoholar.
} 
extremos de los ojos de una raya que le va desde ellos a las orejas. Y aquestos que así están alcoljolados son estimados por una grand dignidad [FOH 3, 53]

[c. 1625 América] indios valientes, membrudos, corpulentos y belicosos, siempre andan alcoholados los ojos [VEC 80]

[1762 Santo Domingo] con (jagua) se arcojolavan los indios [PHC 1, 249]

El arabismo proviene del calco árabe $k a h h a l^{65}$ que hace referencia al proceso de 'ennegrecer con alcohol los bordes de los párpados, las pestañas, las cejas o el pelo' según el $D L E^{66}$.

\subsection{Alijar}

Castañeda utiliza esta voz para explicar las rancherías, es decir, el conjunto de viviendas de los teyas ${ }^{67}$, otro grupo nómada de las llanuras:

dieron en otras rrancherias a quatro jornadas a manera de alixares $\left\{\right.$ GL. $\left[{ }^{\wedge}\right.$ alixares $\left.]\right\}$ era tierra muy poblada donde auia muchos frisoles y siruelas como las de Castilla y parrales [fol. 83r]

Por el contexto en el que aparece, la exuberancia de la flora (frisoles, ciruelas y parrales «como las de Castilla») parece aludir a los alijares granadinos, casas de campo destinadas al disfrute de los sultanes nazaríes en las afueras de la ciudad ${ }^{68}$. No obstante, como ranchería se refiere a casas pobres o aduares, a saber, 'campamento de beduinos, formado por tiendas y chozas' además de usarse en Argentina y Perú en la tercera acepción 'ranchería de indios americanos ${ }^{69}$, creemos que este es el sentido. Es importante notar que el arabismo aparece glosado en el margen derecho del folio 83r del manuscrito, tal y como se muestra en la imagen:
En este texto las glosas se emplean cuando se quiere corregir una errata o bien resaltar, como parece que es el caso, una denominación particular. Es de notar asimismo, que un buen número de glosas en este texto se relacionan con características etnográficas de los indígenas, tales como indumentaria (naguas, fol. $101 \mathrm{v}$ ), arquitectura (patios, fol. 105v), instrumentos (barbacoa, fol. 122v) y prácticas (cruz entre los indios, fol. 152v). En todos estos casos las glosas parecen llamadas de atención al lector en cuanto a las características del Otro.

Por último, desde el punto de vista semántico, las distintas y diversas acepciones mostradas por los repertorios lexicográficos, revelan que su significado no se ha interpretado con unanimidad ${ }^{70}$.

\subsection{Atambor}

En la Relación se emplea para describir rituales indígenas a la par que evocar paralelismos con la cultura árabe. En concreto, Castañeda se refiere al tambor de los anasazis, tribu indígena oasisamericana que ocupaba la superficie de los estados actuales de Colorado, Utah, Arizona y Nuevo México. La cita hace alusión a la llegada de los españoles al pueblo Cicuye (Pecos), donde viven los towa.

salieron a rrecebir a Hernando de Aluarado y a su capitan con muestras de alegria y lo metieron en el pueblo con atambores y gaitas que alli ay muchos a manera de pifanos [fol. 51r]

En el $D C E C H$ se halla explícitamente comentada la conexión entre el referente, la denominación árabe y la realidad musulmana a la que alude ${ }^{71}$ :

Así en el Cid como en la Ch[anson] de Roland, en los historiadores latinos de las Cruzadas y en

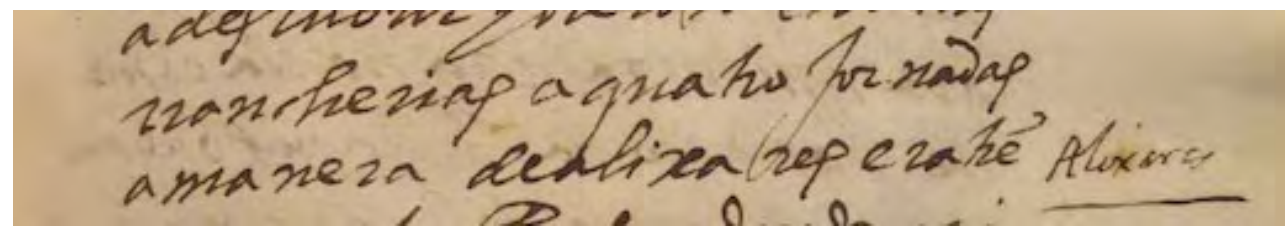

Figura 1: Alixares como glosa [fol. 83r].

65 Corriente, Dictionary, s.v.

66 DLE, s.v.

67 Los teyas, considerados jumanos por Hickerson (The Jumanos, pp. 23-24), eran los enemigos de los querechos.

${ }_{68}$ DCECH, s.v. alijar I.

${ }^{69}$ DLE, s.v. aduar.
70 Esta ausencia de consenso en cuanto al significado de la denominación es habitual en el caso de muchos arabismos (Carriazo Ruiz y Giménez Eguíbar, "Los arabismos léxicos", pp. 363-382).

${ }^{71}$ DCECH, s.v. tambor. 
muchos textos medievales los tambores aparecen sólo como instrumento usado por los musulmanes, y españoles y franceses se refieren a la impresión que este ruido bélico extranjero causaba entre los cristianos.

Como se ha venido demostrando, los paralelos entre ambos grupos étnicos se establecen mediante los arabismos léxicos y a la par que se convierten en los elementos repetidos de esta particular tradición discursiva.

\subsection{Borceguí}

Castañeda utiliza el arabismo en la descripción de las mujeres teya:

es gente bien entendida y las mugeres bien tratadas $\mathrm{y}$ de berguença cubren todas sus carnes $\operatorname{tr}\left[{ }^{*} \mathrm{a}\right]$ en çapatos y borseguiez de cuero adobado [fol. 84r]

Los borceguíes son 'calzado que llegaba hasta más arriba del tobillo, abierto por delante y que se ajustaba por medio de correas o cordones', según el $D L E^{72}$. Aunque la etimología de la denominación esté todavía por aclarar ${ }^{73}$, lo cierto es que la tradición lexicográfica hispánica lo ha venido considerando como arabismo: el padre Alcalá (1505) lo incluye dentro de su repertorio de voces árabes ${ }^{74}$, así como también Eguilaz y Yanguas ${ }^{75}$. Dado que es un vocablo ajeno a los idiomas germánicos y de aparición temprana «casi tan antigua como en francés, lo que invitaría a buscar un origen árabe, teniendo en cuenta la terminación en $-i$, y la antigua fama de los fabricados en Marruecos, atestiguada por los romances $\rangle^{76}$, lo relevante es que, al menos en la época, la denominación se creía de origen árabe y el objeto que designaba se asociaba con la población morisca: «y sólo tres tiene nuestra lengua que son moriscos y acaban en $i$, y son borceguí, zaquizamí y maravedí» ${ }^{77}$. El testimonio más relevante de esta asociación se halla en la entrada del Thesoro de Covarrubias: «Deste calçado vsan los ginetes, y particularmente los Moros, y los de Marruecos han tenido fama» ${ }^{78}$.

72 DLE, s.v.

73 Ni DCECH, s.v., ni Corriente, Dictionary, s.v., lo consideran arabismo.

$74 \quad$ NTLLE, s.V.

75 Eguilaz y Yanguas, Glosario etimológico, p. 348.

76 Pezzi Martínez, “Origen oriental”, p. 80.

77 Quijote, parte II, cap. LXVII (apud Pezzi Martínez, "Origen oriental", p. 80).

78 NTLLE, s.v. borzegvi.

\subsection{Enjalma}

En la descripción de los llanos de los bisontes y sus gentes, es decir, los querechos, se utiliza este arabismo ${ }^{79}$.

a. andan como alarabes con sus tiendas y harrias de perros aparejados con lomillos y enxalmas y sincha quando se les tuerçe la carga aullan llamando quien los aderese [fol.120v]

En los Procesos de Luis de Carvajal (el Mo$z o)^{80}$, texto coetáneo a la Relación, se usa en la descripción de rituales indígenas:

b. [1595 Ciudad de México] habiéndose puesto (...) una enjalma diciendo que era aquélla como la casulla con que los sacerdotes decían la misa.

La lexicografía de la época también relaciona el arabismo con el referente al que alude a la vez que a la comunidad lingüística a la que se adscribe su uso, hecho que indica su estatus de estereotipo lingüístico ${ }^{81}$ : se trata, en palabras de Covarrubias, de 'cierta manera de aluardoncillo, de que vsan los moriscos'; añade «la G. mudamos en S. y decimos Salma, pero el Morisco trueca la $S$. en $X$., y dize Xalma». Bajo enjalma añade 'cierto género de albardoncillo Morisco, labrado de paños de diferentes colores, nombre Arabigo' ${ }^{82}$.

\section{Conclusiones}

En este trabajo nos hemos ocupado de cinco voces de origen árabe (alárabe, alcoholar, alijar, atambor y enjalma), un posible arabismo (borcegui), un latinismo de posible transmisión andalusí (albarrada) y cuatro denominaciones y frases relacionadas directamente con la realidad musulmana (Berbería, Esteban el Negro, morisco, El Turco), además de otras dos (Bigotes, Ysopete) que resaltan la importancia del aspecto físico y/o racial del Otro. Estas unidades

\footnotetext{
79 Del romance andalusí y árabe andalusí *iššálma $<$ latín tardío salma $<$ latín sagma, este del griego < ságma.

80 LHA, s.v.

81 Labov, Language in the Inner City, pp. 237-251. Los estereotipos son marcadores sociolingüísticos que la comunidad reconoce conscientemente como tales pero que no corresponden necesariamente a la actuación lingüística real de los hablantes. Se trata de un rasgo definitorio de un grupo social y generalmente se percibe, erróneamente, como categórico.

82 NTLLE, s.v. xalma.
} 
se usan en la Relación de la jornada de Cíbola para la caracterización y representación de los indígenas del suroeste de los Estados Unidos y su cultura.

Una vez presentado el texto y enmarcado nuestro estudio desde el punto de vista histórico, se han señalado los procedimientos, acordes con la ideología y la tradición discursiva de la época, empleados en la descripción del Otro a través de realidades conocidas para el lector. La última parte del trabajo se centra en el uso de los arabismos por parte de los conquistadores. Se ha continuado una línea de investigación iniciada por Marcos Maíllo ${ }^{83}$ aunque nos hemos ceñido exclusivamente a la Relación y hemos basado el estudio en fuentes primarias: nuestra propia edición paleográfica. De los arabismos contenidos en esta obra, se han seleccionado solo aquellos que se utilizan en la descripción de realidades indígenas. Posteriormente, se han buscado en crónicas coetáneas con el mismo sentido para el análisis de su función en la Relación.

Un aspecto de relevancia recae en el análisis de este vocabulario desde el punto de vista histórico, así como el encuadre dentro del marco teórico de las tradiciones discursivas. Solo así se pueden situar elementos lingüísticos en su contexto y observar, como menciona Gallegos Shibya, «los modelos o esquemas que guían la producción y recepción de cualquier texto o discurso ${ }^{84}$. Siguiendo a este autor, las tradiciones discursivas constituyen dimensiones «histórico-contingentes que, si bien rebasan los límites de las lenguas individuales, seleccionan en estas el uso de una variante lingüística o modelos verbalizados determinados $\rangle^{85}$. Tanto los arabismos como las semejanzas con el mundo árabe cumplen así con una función en la construcción de este modelo verbalizado.

El análisis de estas voces en los textos novohispanos dentro del marco de su tradición discursiva, permite identificar con mayor exhaustividad las particularidades en el desarrollo (o comportamiento) de estos elementos léxicos, a saber, la función de estos arabismos dentro de los hábitos comunicativos de esta tradición, porque se hacen las mismas consideraciones al describir los sistemas de gobierno de los incas y los aztecas que de los sultanatos norteafricanos u otomanos ${ }^{86}$. Estos

\footnotetext{
83 Marcos Má́llo, "Los arabismos más utilizados”, pp. 228-235.

84 Gallegos Shibya, "Tradiciones discursivas", p. 170.

85 Gallegos Shibya, "Tradiciones discursivas", p. 170.

86 García-Arenal, "Moriscos e indios".
}

paralelismos y analogías entre el mundo árabe y el mundo indígena se materializan desde el punto de vista léxico con la utilización de voces árabes con el objeto de reforzar la idea mesiánica de las empresas expansivas de la Corona.

Respecto a las realidades etnoculturales de la región de Cíbola, se bautizan con estas denominaciones: grupos humanos (alárabe, morisco de Berbería y El Turco), construcciones (albarrada, alijar), rituales religiosos (atambor), instrumentos (enjalma), vestimenta (borcegui), atributos y costumbres (alcoholar). Todas estas voces tienen unas connotaciones concretas y su uso está asociado con grupos semíticos, como el caso de alárabe, alijar, alcoholar, atambor, borcegui y enjalma. Además, las denominaciones cumplen con la finalidad de evocar en el lector imágenes del sempiterno enemigo de la Corona: el musulmán, norteafricano u otomano, a la hora de describir a las gentes que habitan en un ignoto y temible territorio americano. Se utiliza el gentilicio alárabe para hacer referencia a los grupos indígenas; albarrada para aludir a una construcción defensiva asociada con la Reconquista; alixar para evocar imágenes que recuerdan la exuberancia y fertilidad de los jardines nazaríes o para denotar los campamentos de los beduinos; atambor para conectar con la imagen del avance de las tropas musulmanas; borceguí recuerda la vestimenta del colectivo morisco y, por último, enjalma al evocar a los arrieros moriscos y a su modo de transporte. No es de extrañar que cinco de los siete arabismos léxicos analizados se usen con referencia a los indígenas nómadas, a saber, los querechos y los teyas, puesto que se consideraban los menos civilizados, sin vivienda fija, y por ende, los más parecidos a los beduinos.

Muchos de estos arabismos eran estereotipos lingüísticos ya en la época y se insertan en descripciones etnográficas, ricas en los elementos raciales. Por último y no por ello menos importante, se vuelve a comprobar la influencia de la historia en la evolución del léxico así como la importantísima imbricación de ambos.

\section{Bibliografía}

Ahern, Maureen, "La narración cartográfica de $L a$ Relación de la Jornada de Cíbola", en Salvador García Castañeda (coord.), Literatura de viajes. El Viejo Mundo y el Nuevo, Madrid, Castalia, 1999, pp. 51-60. 
Arié, Rachel, “Acerca del traje musulmán en España desde la caída de Granada hasta la expulsión de los moriscos", Revista del Instituto Egipcio de Estudios Islámicos, 13 (1965-1966), pp. 103-117.

Bastardín Cardón, Teresa, "La adaptación del fondo léxico patrimonial en la Historia general de las cosas de Nueva España", Boletín de Filología, 48, 1 (2013), pp. 33-52.

Becker, Martin G., "Tradiciones discursivas y cambio lingüístico: el caso del futuro de subjuntivo", en Mónica Castillo Lluch y Lola Pons Rodríguez (eds.), Así se van las lenguas variando. Nuevas tendencias en la investigación del cambio lingüístico en español, Berna, Peter Lang, 2011, pp.105-130.

Bravo-García, Eva y Cáceres-Lorenzo, María Teresa, $L a$ incorporación del indigenismo léxico en los contextos comunicativos canario y americano (1492-1550), Berna, Peter Lang, 2011.

Buesa Oliver, Tomás y Enguita Utrilla, José María, Léxico del español de América: su elemento patrimonial e indígena, Madrid, Mapfre, 1992.

Bunes Ibarra, Miguel Ángel, "El descubrimiento de América y la conquista del Norte de África: dos empresas paralelas en la Edad Moderna", Revista de Indias, 45, 175 (1985), pp. 225-233.

Carriazo Ruiz, José Ramón y Giménez Eguíbar, Patricia, "Los arabismos léxicos de los siglos XVI-XVII a través de los inventarios postmortem conservados en el Archivo del Monasterio de Yuso", en Analecta Malacitana. Anejo CIII. QUAN SABIAS E QUAM MAESTRAS. Disquisiciones de lengua española, Málaga, Analecta Malacitana, 2019, pp. 363-382.

$C O R D E=$ Real Academia Española: Banco de datos (CORDE), Corpus diacrónico del español, [en línea], disponible en: <http://www.rae.es/>, [consultado el 15/02/2020].

CORDIAM = Academia Mexicana de la Lengua: Corpus Diacrónico y Diatópico del Español, [en línea], disponible en: <http://www.cordiam.org/>, [consultado el 15/02/2020].

Corriente, Federico, Dictionary of Arabic and Allied Loanwords: Spanish, Portuguese, Catalan, Gallician and Kindred Dialects, Leiden, Brill, 2008.

Craddock, Jerry R., "Pedro de Castañeda y Nájera, Relación de la jornada de Cíbola: acotaciones gramaticales y léxicas", UC Berkeley, Research Center for Romance Studies, (2010), [en línea], disponible en: <https://escholarship.org/uc/item/8dn472wk> [consultado el 15/02/2020].

$D C E C H=$ Corominas, Joan y Pascual, José Antonio, Diccionario crítico etimológico castellano e hispánico, Madrid, Gredos, 1980-1991.

DHLE = Real Academia Española, Diccionario histórico de la lengua española, Madrid, Seminario de
Lexicografía, 1960-1996, [en línea], disponible en: $<$ https://www.rae.es/> [consultado el 15/02/2020].

$D L E=$ Real Academia Española y Asociación de Academias de la Lengua Española, Diccionario de la lengua española, 23 ${ }^{\mathrm{a}}$ ed., Madrid, Espasa, 2014, [en línea], disponible en: $<$ http://dle.rae.es/ $>$ [consultado el 15/02/2020].

Eguilaz y Yanguas, Leopoldo, Glosario etimológico de las palabras españoles (castellanas, catalanas, gallegas, mallorquinas, portuguesas, valencianas y bascongadas). De origen oriental (árabe, hebreo, malayo, persa y tuco), Granada, Imprenta de la Lealtad, 1886.

Escudero Baztán, Juan Manuel, “La Relación de la jornada de Cíbola de Pedro Castañeda de Nájera como una política del fracaso", Romance Notes, 55 (2015), pp. 35-43.

Flint, Richard, No Settlement, No Conquest: A History of the Coronado Entrada, Albuquerque, University of New Mexico Press, 2008.

Flint, Richard y Flint, Shirley Cushing, Documents of the Coronado Expedition, 1539-1542, Dallas, Southern Methodist University Press, 2005.

Gallegos Shibya, Alfonso, "Tradiciones discursivas y variación lingüística: dos fenómenos de cambio lingüístico complementarios", en Mónica Castillo Lluch y Lola Pons Rodríguez (eds.), Así se van las lenguas variando. Nuevas tendencias en la investigación del cambio lingüístico en español, Berna, Peter Lang, 2011, pp.105-130.

García-Arenal, Mercedes, "Moriscos e indios. Para un estudio comparado de métodos de conquista y evangelización”, Chronica Nova, 20 (1992), pp. 153-175.

García Icazbalceta, Joaquín, Vocabulario de mexicanismos comprobado con ejemplos y comparado con los de otros países hispano-americanos, México, La Europea, 1899, [en línea], disponible en: <https:// books.google.com/> [consultado el 15/02/2020].

Giménez Eguíbar, Patricia, "Algunas cuestiones sobre la pérdida de arabismos", Romance Philology, 64 (2010), pp. 185-196.

Giménez Eguíbar, Patricia, "Dos casos de sustituciones léxicas: los arabismos alfayate y alfajeme", en José María García Martín. (ed.), Actas del IX Congreso Internacional de Historia de la Lengua Española (Cádiz, 2012), Madrid/Frankfurt, Iberoamericana/ Vervuert, 2015, pp. 1413-1427.

Giménez Eguíbar, Patricia, “Attitudes Toward Lexical Arabisms in $16^{\text {th }}$-Century Spanish Texts", en Sandro Sessarego y Fernando Tejedo-Herrero (eds.), Spanish Language and Sociolinguistic Analysis, Amsterdam, John Benjamins, 2016, pp. 363-380. 
Giménez Eguíbar, Patricia, "Hacia una elaboración del tecnolecto agrícola: los arabismos léxicos en el Libro de Agricultura (1513-1539) de Gabriel Alonso de Herrera", en Sonia Kania y Cynthia Kauffeld (eds.), Hispano-Romance Historical Linguistics and Lexicography: A Tribute to John J. Nitti, Nueva York, Hispanic Seminary of Medieval Studies, 2020, pp. 33-64.

Giménez-Eguíbar, Patricia y Kania, Sonia, "Los indigenismos léxicos en la Relación de la jornada de Cíbola: la americanización del español”, Revista de Filología Española, CI, 2, (2021), pp. 331-359.

Guadix, Diego de, Diccionario de arabismos: recopilación de algunos nombres arábigos que los árabes pusieron a algunas ciudades y otras muchas cosas, María Águeda Moreno Moreno (ed.), Jaén, Universidad de Jaén, [1593] 2007.

Hickerson, Nancy P., The Jumanos: Hunters and Traders of the South Plains, Austin, University of Texas Press, 1994.

Julyan, Robert, The Place Names of New Mexico, ed. rev., Albuquerque, University of New Mexico Press, 1998.

Kabatek, Johannes, "Tradiciones discursivas y cambio lingüístico", Lexis: Revista de lingüística y literatura, 29, 2 (2005), pp. 151-177.

Kania, Sonia y Gago Jover, Francisco (eds.), Colonial Texts. Digital Library of Old Spanish Texts, Hispanic Seminary of Medieval Studies, 2018-, [en línea] disponible en: $<$ http://www.hispanicseminary.org/t\&c/ col/index.htm $>$ [consultado el 15/02/2020].

Kania, Sonia, Kauffeld, Cynthia y Sanz-Sánchez, Israel (eds.), Texts and Concordances of the "Relación de la jornada de Cíbola" by Pedro de Castañeda de Nájera (1596), Nueva York, Hispanic Seminary of Medieval Studies, CD-ROM, 2017.

Kessell, John L., Spain in the Southwest: A Narrative History of Colonial New Mexico, Arizona, Texas, and California, Norman, University of Oklahoma Press, 2002.
Labov, William, Language In The Inner City: Studies In The Black English Vernacular, Philadelphia, University of Pennsylvania Press, 1972.

$L H A=$ Harris-Northall, Ray y Nitti, John J. (eds.). Peter Boyd-Bowman's Léxico hispanoamericano 14931993, Nueva York, Hispanic Seminary of Medieval Studies, 2003-2007, [en línea] Ivy A. Corfis, Pablo Ancos, Fernando Tejedo y Philip Tibbetts (eds.), [en línea], disponible en: <https://textred.spanport.lss. wisc.edu $>$ [consultado el 15/02/2020].

Manseau, Peter, One Nation, Under Gods: A New American History, Nueva York, Little, Brown, 2015.

Marcos Maíllo, Ana, "Los arabismos más utilizados por los conquistadores de Nueva España en el siglo XVI", Res Diachronicae, 2 (2003), pp. 230-237.

Menéndez Pryce, América, "Léxico de Cuba: panorama geolectal”, en Milagros Aleza Izquierdo y Julia Sanmartín Sáez (coords.), Estudios de lexicografía y léxico cubanos, Valencia, Universitat de València, 2004, pp. 101-118.

Morínigo, Marcos A., "La formación léxica regional hispanoamericana", Nueva Revista de Filología Hispánica, 7, 1/2 (1953), pp. 234-241.

$N T L L E=$ Real Academia Española: Banco de datos (NTLLE), Nuevo tesoro lexicográfico de la lengua española, [en línea], disponible en: $<\mathrm{http}$ //buscon. rae.es/ntlle/SrvltGUILoginNtlle $>$ [consultado el 15/02/2020].

Pezzi Martínez, Elena, “Origen oriental del vocablo borceguí, Miscelánea de estudios árabes y hebraicos, 27-28 (1979), pp. 79-109.

Riley, Carroll L., Rio de Norte: People of the Upper Rio Grande from earliest times to the Pueblo Revolt, Salt Lake City, University of Utah Press, 1995.

Torres Torres, Antonio, Procesos de americanización del léxico hispánico, Valencia, Universitat de València, 2004.

Valdés Bernal, Sergio, Inmigración y lengua nacional, La Habana, Editorial Academia, 1994. 